\title{
3-D BASE CONTROL SYSTEMS FOR THE SEISMIC PROTECTION OF POWER PLANT EQUIPMENT AND BUILDINGS
}

\author{
Peter Nawrotzki $^{1}$, Victor Salcedo ${ }^{2}$, and Daniel Siepe ${ }^{3}$ \\ ${ }^{1}$ Managing Director, GERB Schwingungsisolierungen GmbH\&Co.KG, Berlin, Germany \\ (peter.nawrotzki@gerb.de) \\ ${ }^{2}$ Vice President, GERB Vibration Control Systems, Inc., Lisle, IL \\ ${ }^{3}$ Project Engineer, GERB Engineering GmbH, Essen, Germany
}

\begin{abstract}
Reactor buildings, nuclear islands and similar seismic category 1 equipment-structures in nuclear facilities can be protected utilizing carefully applied principles. This offering presents some earthquake control strategies utilizing proven 3-dimensional Base Control Systems (BCS) consisting of helical steel springs and viscous dampers. Some examples are offered showing the benefits and improved seismic performance of these structures while effectively dealing with the strong vertical input long addressed by extremely robust design and construction. BCS allows the tuning of rigid body modes into the low frequency range, while offering high damping values in all three spatial directions. This results in drastically reduced seismic acceleration levels of safety and non-safety related structures without increasing design and construction effort of high-tuned structures.

This contribution illustrates the results of numerical analyses and measurements of real structures using BCS. A 3-dimensional building structure is numerically investigated by finite elements and the effects of the proposed protection system are discussed. As expected lower accelerations and support reaction loads also yield reduced floor response spectra.

Lastly some practical examples present the high efficiency of the suggested control system for the protection of equipment and buildings against seismic impacts in horizontal and vertical directions.
\end{abstract}

\section{INTRODUCTION}

The mitigation of operational vibration is a driving factor in power plant design. Hence, turbine foundations, condensers, coal mills, fans, boiler feed pumps and other equipment are often elastically supported. The combination of an elastic support system consisting of helical steel springs with the arrangement of viscous dampers leads to tremendous benefits in the design of surrounding building structures, allowing the full integration of turbines and boiler feed pump support structures into the turbine building. This not only leads to a 3-dimensional Base Control System (BCS) in these applications that protects against horizontal forces but also proves highly effective against the combination of horizontal and vertical seismic excitation. Additionally it can also lead to reduced accelerations in the structure tied to the BCS supported equipment.

The successful application in NPPs since the late 1960s lead to the development of BCS for the sole protection of equipment such as steam generators, uranium enrichment pumps and a spent fuel storage pool presented in this paper. Some practical examples of executed projects are used to demonstrate the successful implementation of Base Control Systems., while a detailed example exploring the benefits of BCS as applied to an NPP reactor building is discussed. 


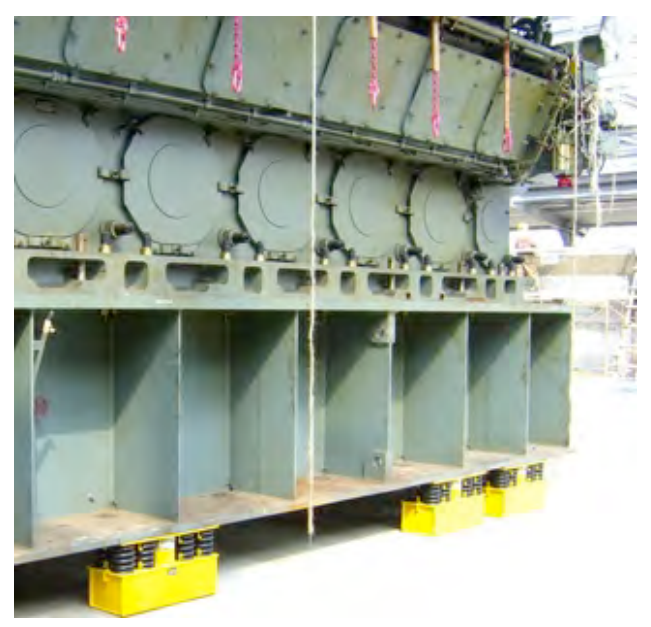

Figure 1. Emergency Diesel Generator with Base Control System.

The 3-dimensional Base Control System consists of helical steel springs and highly efficient viscous dampers (Viscodampers), typically arranged below the foundation or the base frame of the equipment. Figure 1 shows a typical elastically supported emergency diesel generator set (EDG) in a nuclear power plant (NPP). The system is flexible in the horizontal directions, but also exhibits vertical elasticity. The dampers also work in all directions, thus they supply dissipative forces in horizontal and vertical directions.

Increasing the fundamental period, or lowering structural frequency, is an efficient seismic control strategy. The benefit of lowering the modal frequency in combination with the modification of the mode shape can be taken from Figure 2.

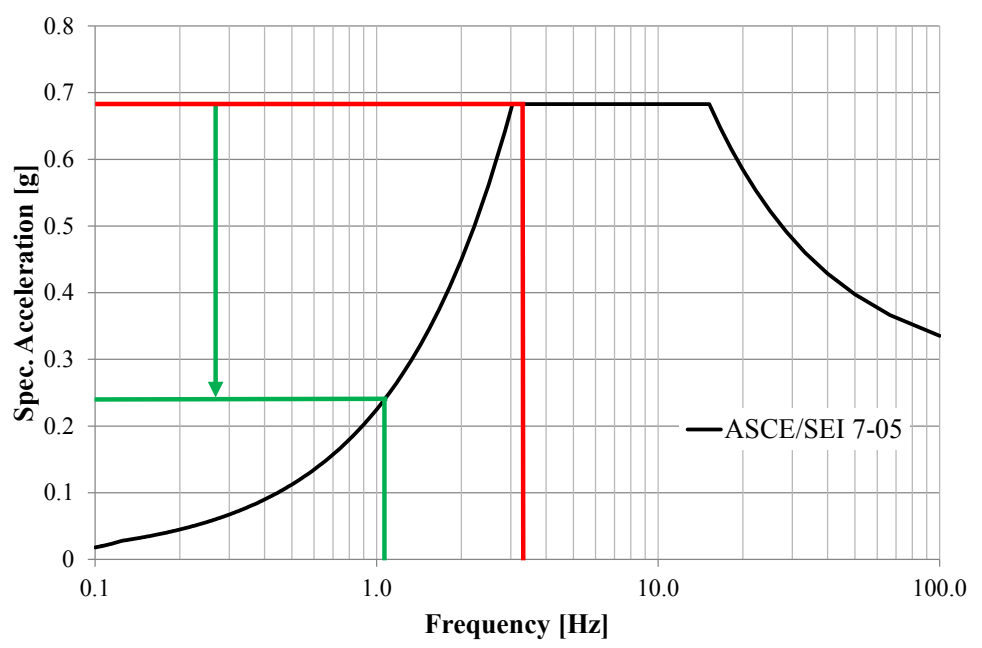

Figure 2. Typical effect of frequency reduction.

Here, the response spectrum according to ASCE/SEI 7-05 (2006) is plotted for site class B, It effectively illustrates the potential benefits of a passive control measure that moves system frequencies into the low end of the spectrum. Already a shift from the assumed frequency of about $3.5 \mathrm{~Hz}$ for the rigid system, to about $1.0 \mathrm{~Hz}$ leads to lower seismic demand of about $0.25 \mathrm{~g}$ versus $0.68 \mathrm{~g}$ at the original frequency. Damping also plays an essential role in reducing seismic demands. Various national and international standards illustrate the increase in damping as a benefit. 
According to Figure 3, an increase of structural damping from $5 \%$ to $12 \%$ causes a further reduction of acceleration in the range of $25 \%$. Spring and viscous dampers offer both the ability to adjust the frequency of the system as well as dramatically increase the amount of structural damping.

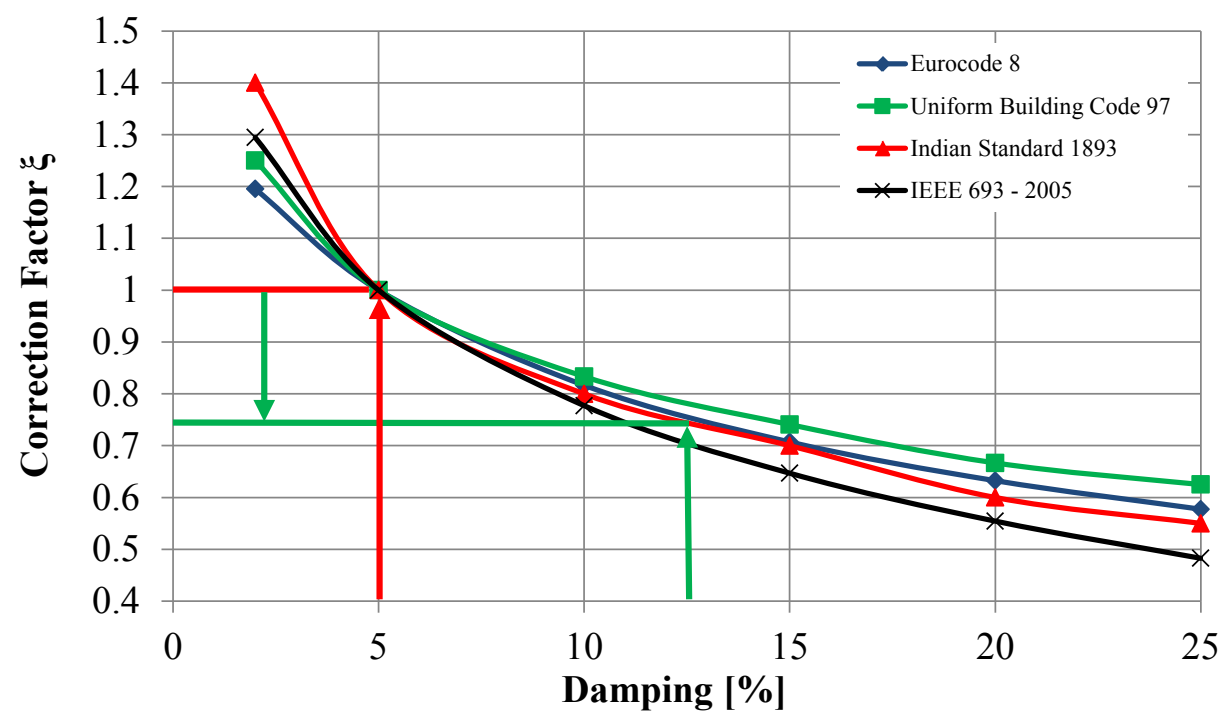

Figure 3. Typical effect of damping increase.

The combined results of reducing system frequencies while also increasing structural damping yields optimal seismic protection of a structure by reducing accelerations and hence internal stresses. These effects are verified by theoretical and experimental investigations, and discussed for example, in Rakicevic et al. (2006). For actual measured responses of two occupied structures subjected to a seismic event showing the efficiency of the installed BCS, refer to Stuardi et al. (2008).

As a course of governing standards and regulations, safety related structures in nuclear power plants must be designed for any possible earthquake events. Standard design procedures can result in extremely robust/large structures. It is possible however to reduce this effort by placing an entire reactor building onto a Base Control System (BCS). In this case, the induced seismic accelerations and stresses within the supported structure are relatively small. In addition to the increase of seismic safety of the building, the arrangement of a BCS also provides benefits for the seismic design of housed equipment.

\section{SEISMIC PROTECTION OF POWER PLANT EQUIPMENT}

Based on the experience in seismic protection of machinery the same approaches can be applied to control structures, which do not require vibration isolation. Equipment in (nuclear) power plants can be supported by helical steel springs and viscous dampers against excitation due to seismic events and/or aircraft impact. The safety of these structures is of particular interest and they often consist of sensitive material. In the following a spent fuel storage tank is discussed as typical example for this kind of equipment.

Figure 4 shows the top view of the spent fuel storage tank in a nuclear power plant, located in a high seismic zone in Switzerland. The pool dimensions are about $20.0 \times 10.0 \mathrm{~m}(66 \mathrm{x} 33 \mathrm{ft})$ with a height of about $14.0 \mathrm{~m}(46 \mathrm{ft})$. The total operation mass of this structure is approximately 6000 metric tons (13,200 kips). A peak acceleration value of nearly $0.5 \mathrm{~g}$ just below the BCS has to be considered at the base of the tank. An earthquake protection system had to be developed to reduce potentially very high response accelerations. The waves generated from a seismic event on the water surface should not overflow the top of the pool walls and the integrated steel racks should not contact each other. 


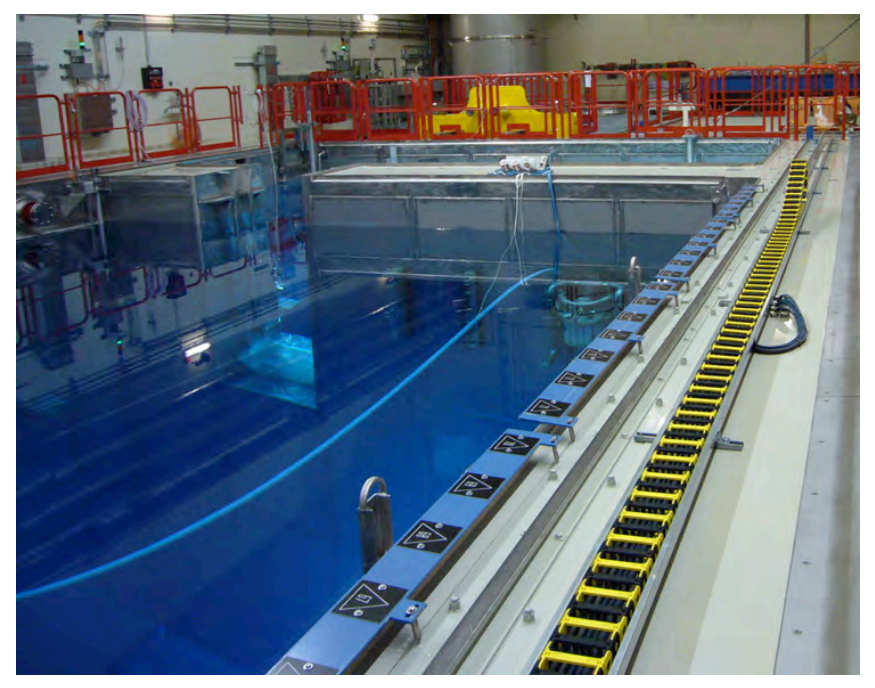

Figure 4. Spent fuel storage tank in NPP.

The Base Control System, consisting of helical steel springs and Viscodampers, is arranged between the pool and surrounding building to fully support the pool load.. These elements were especially designed for the above-mentioned application to yield relatively low structural frequencies of the springsupported system. Simultaneously the damping of the corresponding mode shapes is increased. The combination of these measures reduces acceleration and avoids the overflow of water. Figure 5 shows a part of the BCS below the fuel pool.

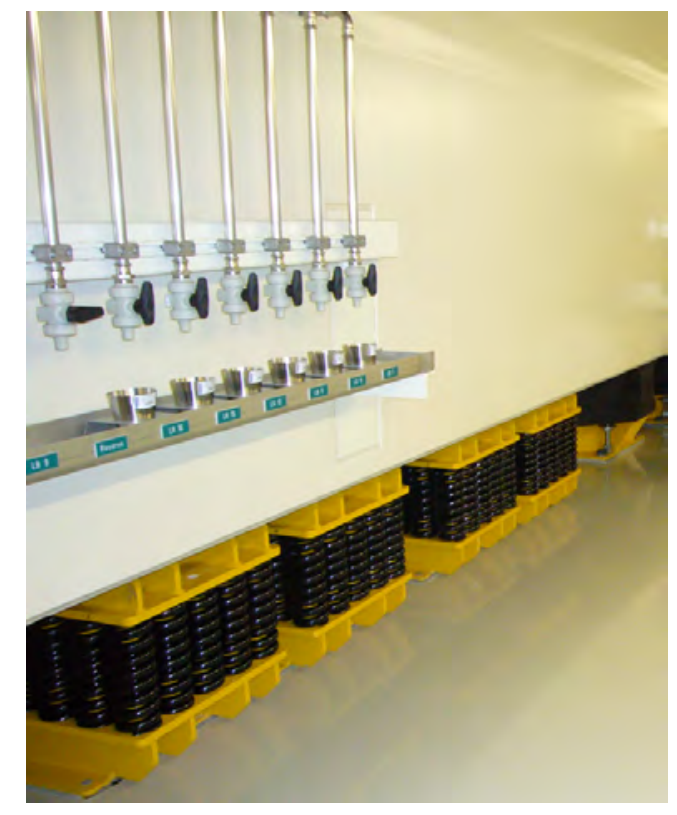

Figure 5. 3-D Base Control System below a spent fuel pool in a high seismic zone.

The system was successfully installed in 2008. As the elements were pre-stressed they served as a rigid support during the construction of the pool itself. One further advantage of this support system is that these elements also allow for easy adjustment of the system in case of later differential settlement or in case of any other modification becomes necessary during the lifetime of the installation. Access to the devices are a design element, thus a visual check of the elements is always possible. 


\section{SEISMIC PROTECTION OF NUCLEAR POWER PLANT BUILDINGS}

Based on the experience from the seismic protection of machinery and equipment it is possible to transfer the control strategies to the protection of different structures. In a nuclear power plant entire buildings and parts of buildings have to be protected against different load scenarios. Due to the devastating events surrounding Fukushima in 2011 the seismic issues are once again under particular scrutiny and become more and more important to safeguard the public.

There are still many current design codes which neglect the vertical ground motion present in an earthquake. For sensitive structures in power plants the effects of both horizontal and vertical excitations must be taken into account. Thus, the development of a control system efficiently working in all three directions is required. Previous investigations according to Chouw (2002) have shown that helical steel springs and viscous dampers are able to reduce the effects of horizontal and vertical ground motions.

For the further evaluation of control systems the experiences from an executed project at Mendoza, Argentina could be used. In 2004, two identical apartment buildings are built. One structure is supported by a Base Control System consisting of springs and Viscodampers. The adjacent building consists of a "rigid" basement. Both structures consist of three floors of reinforced concrete and masonry infill. Total weight of one building is about 260 metric tons. The apartments belong to the National Technological University of Mendoza and are equipped with seismic accelerometers.

During a seismic event with a peak ground acceleration of about $0.12 \mathrm{~g}$ in 2005 the seismic response of the base-controlled building ("BCS") and the structure without control system ("fix. bas.") was measured. Thus, the direct comparison of the two systems under the same seismic excitation is possible. Figure 6 shows the reduction of acceleration at the top of the building in case of the building equipped with BCS. The horizontal peak acceleration value was reduced by more than $70 \%$.

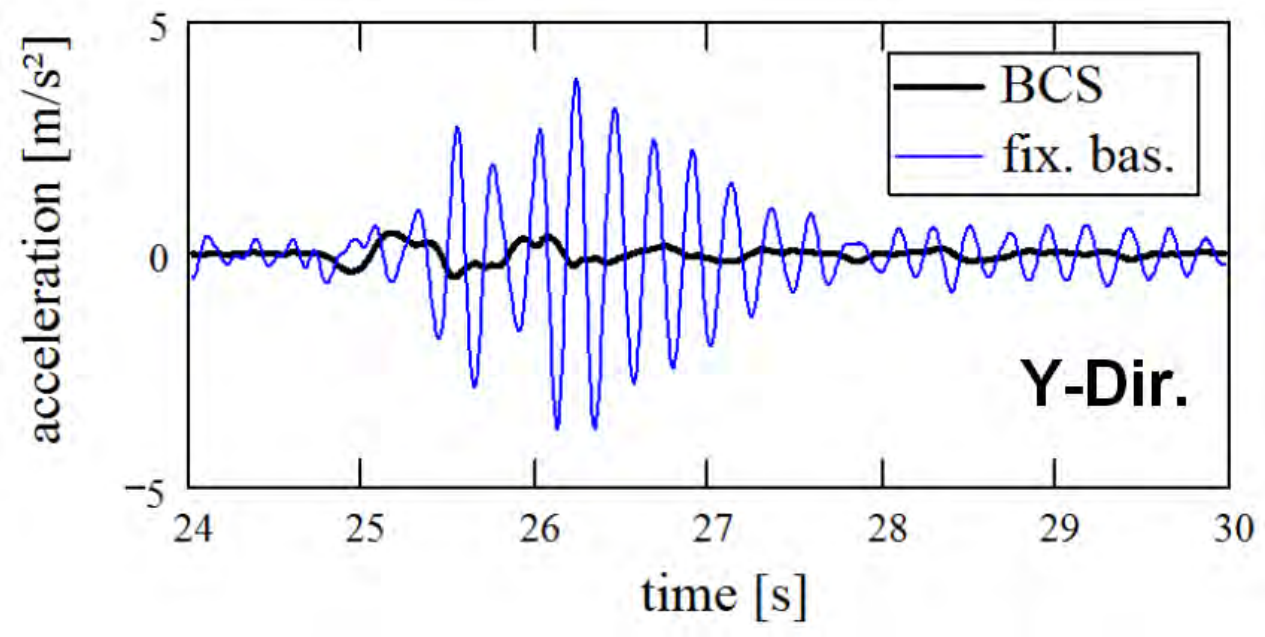

Figure 6. Measured acceleration in horizontal y-direction at top of building.

The measured results are also used to adjust the initial analysis model. Stuardi et al. (2008) show that similar to the acceleration reduction the corresponding responses like internal stresses and subsoil reaction forces could be reduced significantly. Usually it is not possible to measure the behavior of two identical structures, thus several numerical and experimental investigations have been prepared to verify the control strategies and the reliability of the calculations. Gomez et. al. (2012) investigated the application of a Base Control System for a massive concrete structure, located in a high seismic zone, where the vertical seismic input is even higher than the horizontal one. Prototype tests were performed on a shaking-table. The corresponding results established high correlation between the tested and calculated results. 
To assess the reduction effect of a 3-D Base Control Systems on a NPP building structure such as the reactor building, numerical calculations of a structure, weighing approximately 150,000 metric tons (330,000 Kips) was performed. For the feasibility study two different finite element models are prepared. The first model consists of fixed restraints at the bottom plate. The second model considers the identical structure, but supported by a control system below the base mat. A typical base-isolation system, which will lead to an extremely low horizontal stiffness and a high vertical stiffness, may lead to horizontalvertical coupling effects that could amplify the horizontal accelerations according to Ryan et al. (2012).

The properties of the springs and dampers are chosen taking into account horizontal and vertical effects. The structure is idealized as a 3-dimensional finite-element model. The longitudinal axis is the $\mathrm{x}$ axis. The transversal axis is the y-axis. The z-axis is the vertical axis. Figure 7 shows the FE-model and a typical picture of a spring element and a damper below a concrete structure.

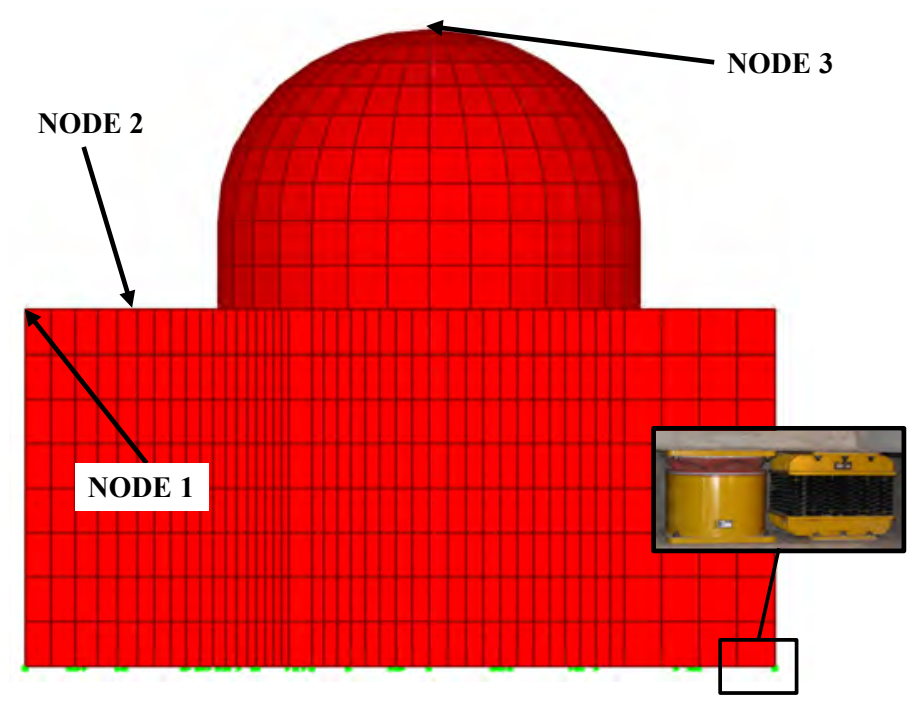

Figure 7. Seismic control system below finite element model of reactor building.

The numerical analysis has been done for the time domain using a ground acceleration time record corresponding to the spectrum shown in Figure 2. As an assumption the same input is used for the horizontal and vertical directions. Figure 8 shows the time record that has been used for the excitations. The calculation considers a simultaneous excitation in all three directions.

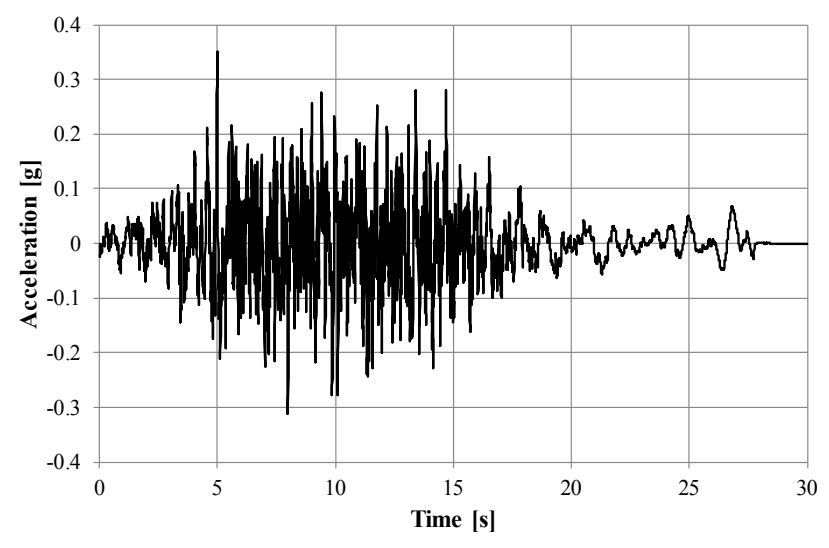

Figure 8. Time record of the applied earthquake. 
Due to the seismic input the dynamic behavior is investigated for both systems. Table 1 shows a comparison of the results evaluated at different nodes of the FE-model. In the horizontal directions it is possible to reduce the accelerations and the base shear by more than $75 \%$ when applying the seismic control system. As the system also functions in the vertical direction, there is a significant reduction effect otherwise not feasible. From these results it can be concluded that even the internal stress and strain values will be reduced in a same order of magnitude.

Table 1: Results of time history analysis.

\begin{tabular}{|c|c|c|c|}
\hline & $\begin{array}{c}\text { Without } \\
\text { BCS }\end{array}$ & $\begin{array}{c}\text { With } \\
\text { BCS }\end{array}$ & $\begin{array}{c}\text { Reduction } \\
{[\%]}\end{array}$ \\
\hline Max. absolute acceleration of node 1 in x-direction [g] & 0.74 & 0.16 & 78.0 \\
\hline Max. absolute acceleration of node 2 in y-direction [g] & 0.77 & 0.17 & 78.4 \\
\hline Max. absolute acceleration of node 3 in z-direction [g] & 0.71 & 0.40 & 42.7 \\
\hline Base shear in x-direction [kN] & 604820 & 142128 & 76.5 \\
\hline Base shear in y-direction [kN] & 597636 & 125144 & 79.1 \\
\hline Sum of forces in z-direction [kN] & 468481 & 387120 & 17.4 \\
\hline
\end{tabular}

Although the internal stresses of the building structure are reduced the effects on the dynamic properties are also important. For the layout and design of equipment inside the reactor building usually floor response spectra are calculated. The efficiency of the Base Control System in this regard can be seen in Figure 9 showing the floor response spectra at a higher elevation of the building structure. In one case ("RIGID") the building is supported by fixed restraints at the base mat in the second case ("BCS") the same structure is supported by a BCS. The peak accelerations are assumed to be constant for a frequency range of $\pm 15 \%$ of the corresponding frequency (frequency widening).
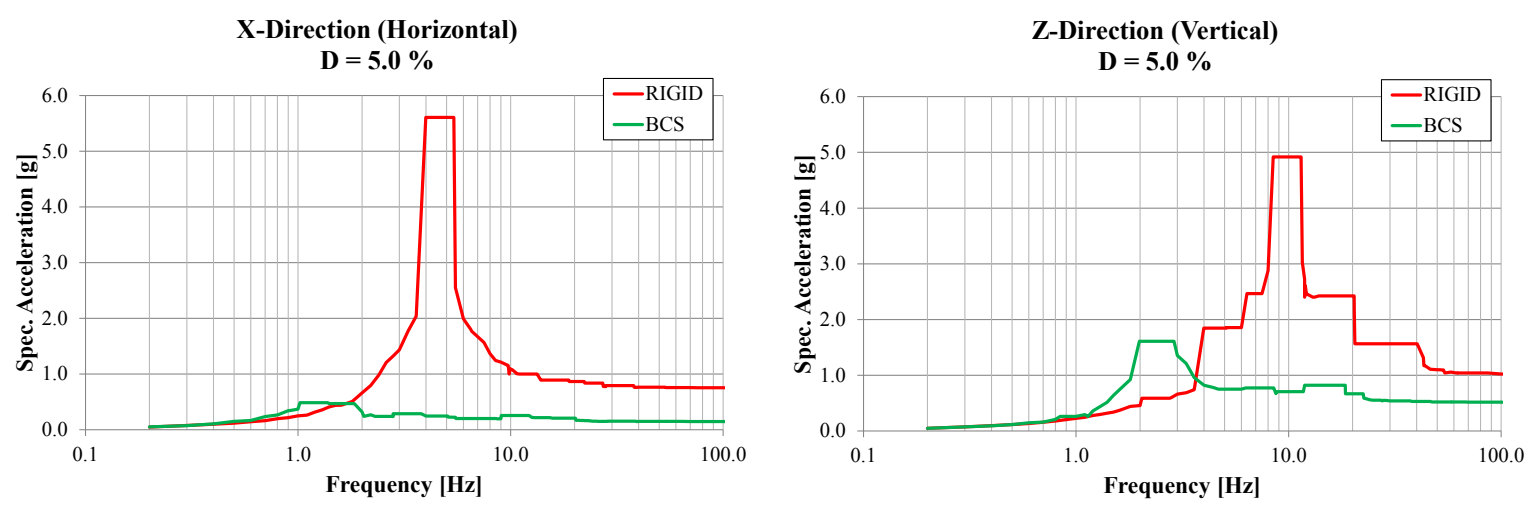

Figure 9. Efficiency of a Base Control System in horizontal and vertical directions.

In light of the presented results it can be summarized that the application of a BCS leads to a significant reduction of the accelerations, base reactions and the spectral values of the floor response spectra in a wide frequency range. 


\section{CONCLUSION}

An approach for the seismic protection of power plant equipment and buildings was investigated and has shown its effectiveness and potential application. After a short introduction into the fundamentals of seismic control strategies, some examples for earthquake protection were discussed especially using Base Control Systems (BCS).

The BCS for buildings in a nuclear power plant were discussed in further detail, comparing the seismic behavior of a structure with and without this elastic support system. Accelerations, support reactions and floor response spectra were calculated. It is shown that the proposed control system leads to a significant reduction of the accelerations, base reactions and the values of the floor response spectra. The use of a 3-dimensional Base Control System should be further investigated for practical application in new NPP buildings and safety related structures.

\section{REFERENCES}

American Society of Civil Engineers. (2006). ASCE/SEI 7-05 Minimum Design Loads for Buildings and Other Structures. American Society of Civil Engineers, Reston, Virginia, USA.

Chouw, N. (2002). "Reduction of the effects of strong vertical ground motions on structural responses," Proc., $7^{\text {th }}$ U.S. National Conference on Earthquake Engineering, Boston, Massachusetts, USA.

Gomez, C., Aviles, A., Bilbao, A., Siepe, D., and Nawrotzki, P. (2012). "E-ELT Seismic Devices Analysis and Prototype Testing," Proc., SPIE Astronomical Telescopes and Instrumentation, Amsterdam, Netherlands.

Rakicevic, Z., Jurukovski, D. and Nawrotzki, P. (2006). "Analytical modeling of dynamic behavior of a frame structure with and without Base Control System," Proc., $4^{\text {th }}$ World Conference on Structural Control and Monitoring, San Diego, USA.

Ryan, K.L, Dao, N.D., Sato, E., Sasaki, T., and Okazaki, T. (2012). "NEES/E-Defense Base-Isolation Tests: Interaction of Horizontal and Vertical Response," Proc., 15 WCEE, Lisbon, Portugal.

Stuardi, J.E., Nawrotzki, P., and Suarez, L.E. (2008). "Comparative seismic performance of a Base Control System based on measured and calculated responses," Proc., 14 WCEE, Beijing, China. 